\title{
Overcoming the High-Voltage Limitations of Li-lon Batteries Using a Titanium Nitride Current Collector
}

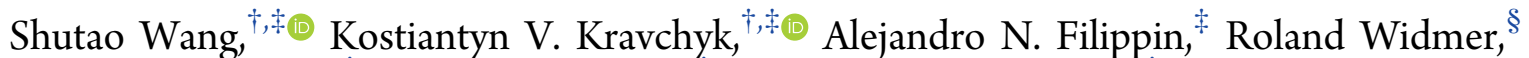
Ayodhya N. Tiwari, ${ }^{\ddagger}$ Stephan Buecheler, ${ }^{\ddagger}$ Maryna I. Bodnarchuk, ${ }^{\ddagger}$ and Maksym V. Kovalenko* ${ }^{*}$, ,

${ }^{\dagger}$ Laboratory of Inorganic Chemistry, Department of Chemistry and Applied Biosciences, ETH Zürich, Vladimir-Prelog-Weg 1, CH-8093 Zürich, Switzerland

${ }^{\ddagger}$ Laboratory for Thin Films and Photovoltaics, Empa-Swiss Federal Laboratories for Materials Science and Technology, Überlandstrasse 129, CH-8600 Dübendorf, Switzerland

${ }^{\S}$ Nanotech@surfaces Laboratory, Empa-Swiss Federal Laboratories for Materials Science and Technology, Überlandstrasse 129, 8600 Dübendorf, Switzerland

Supporting Information

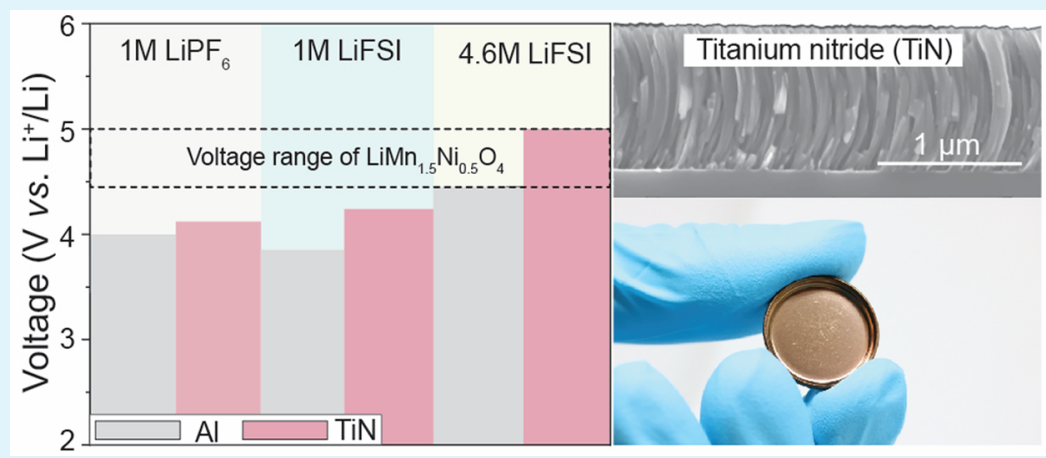

ABSTRACT: The major obstacle to commercialization of high-voltage Li-ion batteries is the lack of oxidatively stable and inexpensive current collectors that can operate at potentials of up to $5 \mathrm{~V} \mathrm{vs} \mathrm{Li}^{+} / \mathrm{Li}$. In this work, we present titanium nitride as a compelling cathode current collector for high-voltage Li-ion batteries exhibiting higher oxidative stability in $\mathrm{LiPF}_{6}$ and lithium bis(fluorosulfonyl)imide electrolytes than aluminum or stainless steel current collectors. Its high oxidative stability has been assessed with a high-voltage $\mathrm{LiMn}_{1.5} \mathrm{Ni}_{0.5} \mathrm{O}_{4}$ cathode. TiN/LiMn ${ }_{1.5} \mathrm{Ni}_{0.5} \mathrm{O}_{4}$ half cells demonstrated a high Coulombic efficiency of $98.5 \%$ at a low C-rate of $0.2 \mathrm{C}$ after 100 cycles.

KEYWORDS: titanium nitride, current collector, high-voltage Li-ion battery, $\mathrm{LiMn}_{1.5} \mathrm{Ni}_{0.5} \mathrm{O}_{4}$, energy density

$\mathrm{R}$ echargeable Li-ion batteries (LIBs) have become a key energy storage technology that has served humanity for over the past two decades in a variety of applications, e.g., portable electronic devices and electric vehicles, owing to the high energy density, long cycling lifetime, and high power performance. $^{1-5}$ The practical energy density of present-day LIBs composed of a graphite anode and $\mathrm{LiCoO}_{2}, \mathrm{LiMn}_{2} \mathrm{O}_{4}$, $\mathrm{LiNi}_{0.33} \mathrm{Mn}_{0.33} \mathrm{Co}_{0.33} \mathrm{O}_{2}$, and $\mathrm{LiFePO}_{4}$ cathodes, however, is approaching the practical limit of $250 \mathrm{Wh} \mathrm{kg}{ }^{-1} \cdot{ }^{6-8}$ In this context, alternative high-voltage cathode materials have been proposed, such as spinel $\mathrm{LiMn}_{1.5} \mathrm{Ni}_{0.5} \mathrm{O}_{4}$ (LMNO), ${ }^{9-12}$ polyanionic $\mathrm{LiVPO}_{4} \mathrm{~F}^{13,14}$ Li-rich layered oxide $\mathrm{Li}_{1.2} \mathrm{Ni}_{0.2^{-}}$ $\mathrm{Mn}_{0.6} \mathrm{O}_{2},{ }^{15,16}$ and $\mathrm{Ni}$-rich layered oxide $\mathrm{LiNi}_{0.8} \mathrm{Co}_{0.1^{-}}$$\mathrm{Mn}_{0.1} \mathrm{O}_{0.2}{ }^{17}$ These materials offer average discharge voltages of $4.2-4.7 \mathrm{~V}$ vs $\mathrm{Li}^{+} / \mathrm{Li}$, which enable an increase in energy densities by up to $25 \%$ or $80 \%$, assuming graphite and metallic lithium, respectively, as anodes. ${ }^{2,18}$ An LMNO cathode is considered to be a particularly attractive candidate for the next generation of LIBs due to its high voltage of $4.7 \mathrm{~V}$ vs $\mathrm{Li}^{+} / \mathrm{Li}$ and relatively large theoretical capacity of $147 \mathrm{mAh} \mathrm{g}^{-1}$ owing to two reversible redox processes, $\mathrm{Ni}^{2+} / \mathrm{Ni}^{3+}$ and $\mathrm{Ni}^{3+} / \mathrm{Ni}^{4+}$, occurring at 4.70 and $4.75 \mathrm{~V}$ vs $\mathrm{Li}^{+} / \mathrm{Li}$, respectively.

However, the overcharging problem of high-voltage cathodes, which involves the oxidation and corrosion of the current collectors, is still not fully resolved. Aluminum ( $\mathrm{Al}$ ) and stainless steel (SS), commonly used cathode current collectors, are not suitable for high-voltage applications, as they often start oxidizing at voltages as low as $3.9^{19,20}$ and $3.1 \mathrm{~V}^{21,22}$ vs $\mathrm{Li}^{+} / \mathrm{Li}$ (depending on the electrolyte used), respectively,

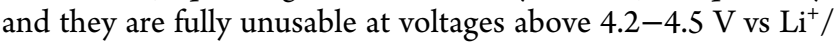
Li. Al can still be applied for most research purposes because its corrosion is often slow enough, but it cannot be used in commercial high-voltage batteries. On the other hand, alternative metals/oxides proposed earlier, such as silver

Received: October 23, 2018

Accepted: February 8, 2019

Published: February 8, 2019 
a

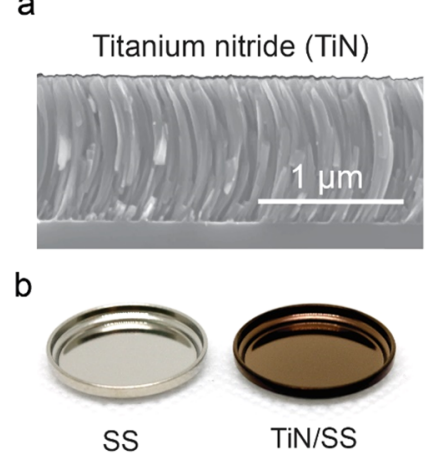

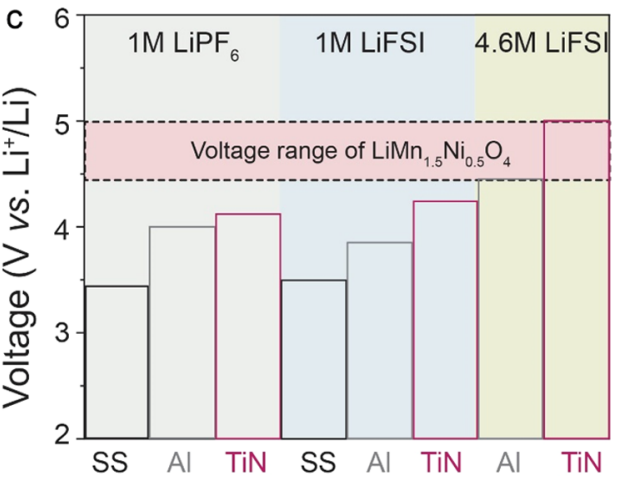

Figure 1. (a) SEM cross-section of a TiN film prepared by magnetron sputtering. (b) Photographs of bare and TiN-coated stainless steel substrates. (c) Illustration of the oxidative stabilities of various current collector materials in $1 \mathrm{M} \mathrm{LiPF}_{6}, 1 \mathrm{M} \mathrm{LiFSI}$, and $4.6 \mathrm{M} \mathrm{LiFSI}$ in EC/DMC electrolytes in terms of the voltage versus $\mathrm{Li}^{+} / \mathrm{Li}$. Oxidative stabilities were derived from cyclic voltammetry curves of the corresponding current collectors obtained at a scan rate of $0.1 \mathrm{mV} \mathrm{s}^{-1}$ (Figure S3).

$(\mathrm{Ag}){ }^{23}$ gold $(\mathrm{Au}){ }^{24}$ platinum $(\mathrm{Pt}){ }^{25}$ molybdenum $(\mathrm{Mo}),{ }^{26}$ tungsten oxide $\left(\mathrm{WO}_{3}\right),{ }^{27}$ and platinum-rhodium alloy $(\mathrm{Pt}-$ $\mathrm{Rh}){ }^{28}$ are prohibitively costly.

Herein, we report that titanium nitride (TiN), a highly electrically conductive material, is highly suited for commercial use as a high-voltage current collector due to its high oxidative stability in $\mathrm{LiPF}_{6}$ - and LiFSI-based electrolytes at potentials of up to at least $5.0 \mathrm{~V}$ vs $\mathrm{Li}^{+} / \mathrm{Li}$. Its practical advantages are the high natural abundance of the constituting elements and low cost of fabrication. Its superior stability toward electrochemical oxidation is presented herein with cells utilizing an LMNO cathode. TiN/LMNO half cells exhibited a high Coulombic efficiency of $\sim 98.5 \%$ at a C-rate of $0.2 \mathrm{C}$ after 100 cycles. A side-by-side comparison of the electrochemical oxidation stability of TiN with those of $\mathrm{Al}$ and SS current collectors is also presented.

Titanium nitride current collectors were prepared on a stainless steel bottom coin-type cell substrate by magnetron sputtering using a $\mathrm{Ti}$ target under a nitrogen-argon atmosphere (Figure 1a,b). Alternatively, for the pouch-type cell configuration, sputtering of $\mathrm{TiN}$ on a flexible polyimide film with a relatively large surface area of $0.1 \mathrm{~m}^{2}$ was also demonstrated (Figure S1). X-ray diffraction measurements (Figure 2) confirmed the formation of a highly crystalline cubic TiN film on stainless steel (space group Fm $3 m, a=4.241$ $\AA$, JCPDS 038-1420) oriented in the [111] direction. The cross-sectional scanning electron microscopy (SEM) image

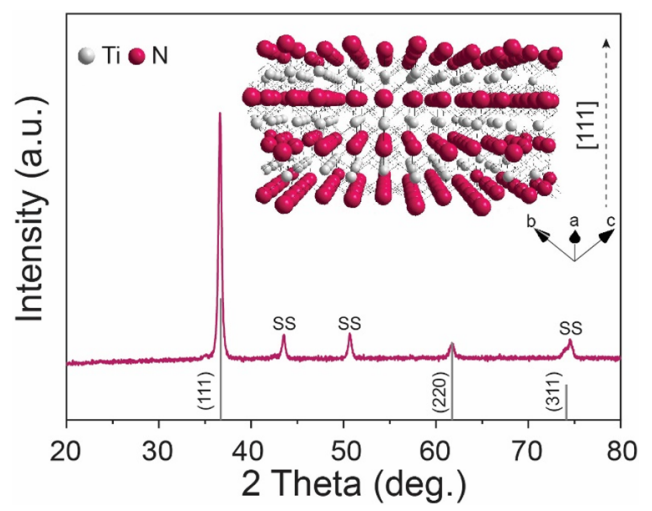

Figure 2. X-ray pattern of TiN film deposited on a stainless steel substrate (inset: crystal structure of $\mathrm{TiN}$ ). shown in Figure 1a reveals a columnar morphology with a thickness of approximately $1 \mu \mathrm{m}$. Top-view SEM images of the samples show that the stainless steel substrate is fully covered by the pinhole-free continuous TiN film (Figure S2).

The electrochemical stability of the TiN current collector was evaluated using $1 \mathrm{M} \mathrm{LiPF} 6$ and $1 \mathrm{M}$ lithium bis(fluorosulfonyl)imide (LiFSI) in ethylene carbonate/dimethyl methyl carbonate (EC/DMC) electrolytes. Figure S3a,b shows the cyclic voltammetry $(\mathrm{CV})$ curves for various current collectors in both electrolytes, and the results are summarized in Figure 1c. The onset of electrochemical oxidation in $\mathrm{LiPF}_{6} /$ LiFSI electrolytes occurs at $3.44 \mathrm{~V} / 3.49 \mathrm{~V}, 4.0 \mathrm{~V} / 3.85 \mathrm{~V}$, and

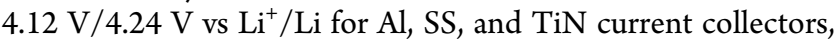
respectively. As shown in Figure 1c, the oxidative stability of $\mathrm{TiN}$ in both electrolytes exceeds those of $\mathrm{Al}$ and SS. The increase in the current above $4.12 \mathrm{~V} / 4.24 \mathrm{~V}$ vs $\mathrm{Li}^{+} / \mathrm{Li}$ in $\mathrm{LiPF}_{6} / \mathrm{LiFSI}$ electrolytes for the TiN current collector could be associated with the oxidation of the $\mathrm{LiPF}_{6}$ and LiFSI electrolytes. The high oxidative stability of the TiN current collectors might be attributed to the preferred (111) orientation (Figure 2) of the $\mathrm{TiN}$ film, as discussed later. We note that, in our previous studies on a TiN current collector for aluminum batteries, the high oxidation stability of TiN was demonstrated even in highly corrosive aluminumbased ionic liquids, outperforming SS, molybdenum, and tungsten current collectors. ${ }^{29}$

Next, the oxidative stability of the TiN current collector was probed in highly concentrated LiFSI-based solutions. These represent a novel class of $\mathrm{Li}$ electrolytes with advantageous properties, such as high oxidative stability, thermal stability, and low volatility, over those of conventional $1 \mathrm{M} \mathrm{LiPF}_{6}$ electrolytes. ${ }^{30}$ In addition, it was recently demonstrated that LiFSI electrolytes sustain reversible plating/stripping of metallic $\mathrm{Li}$, as required for $\mathrm{Li}$ metal/high-voltage cathode batteries. $^{30}$ According to the cyclic voltammetry curves measured at $0.1 \mathrm{mV} \mathrm{s}^{-1}$ (Figures S3c) in highly concentrated 4.6 M LiFSI electrolyte, the onset of electrochemical oxidation occurs at $>5.0$ and $4.45 \mathrm{~V} \mathrm{vs} \mathrm{Li}^{+} / \mathrm{Li}$ for the TiN and $\mathrm{Al}$ current collectors, respectively, highlighting the superior stability of the TiN current collector over that of Al. The electrochemical stabilities of both the $\mathrm{TiN}$ and $\mathrm{Al}$ current collectors in combination with a high-voltage LMNO cathode were probed. Specifically, a series of galvanostatic cycling measurements of $\mathrm{TiN} / \mathrm{LMNO}$ and $\mathrm{Al} / \mathrm{LMNO}$ electrodes was performed to examine the effect of LMNO active material loading on the 

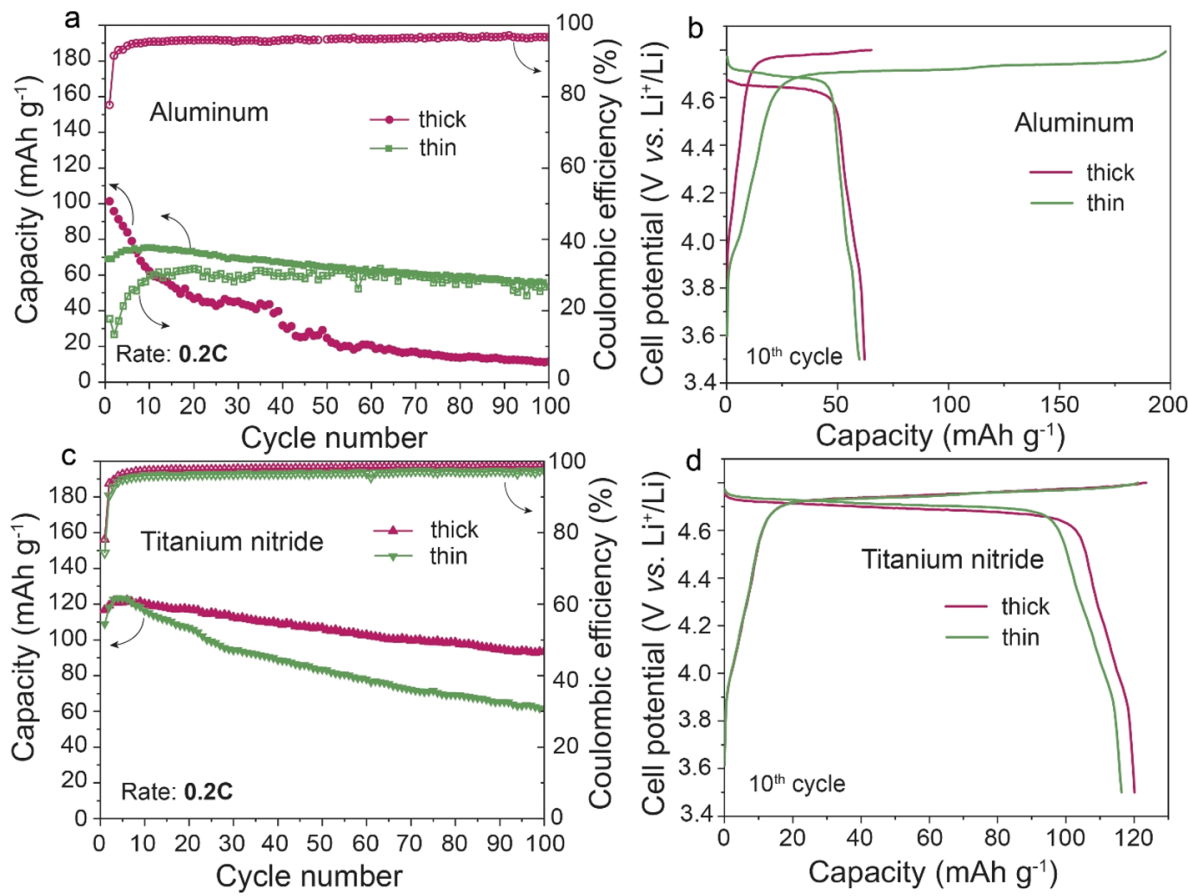

Figure 3. Cyclability/Coulombic efficiency and typical voltage profiles of thick $(\sim 55-60 \mu \mathrm{m})$ and thin $(\sim 15-20 \mu \mathrm{m})$ LMNO cathodes deposited on $\mathrm{Al}(\mathrm{a}, \mathrm{b})$ and $\mathrm{TiN}(\mathrm{c}, \mathrm{d})$ current collectors. The measurements were performed in $4.6 \mathrm{M} \mathrm{LiFSI}$ in EC/DMC electrolyte at a C-rate of $0.2 \mathrm{C}$ ( $1 \mathrm{C}$

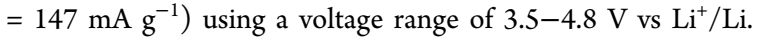
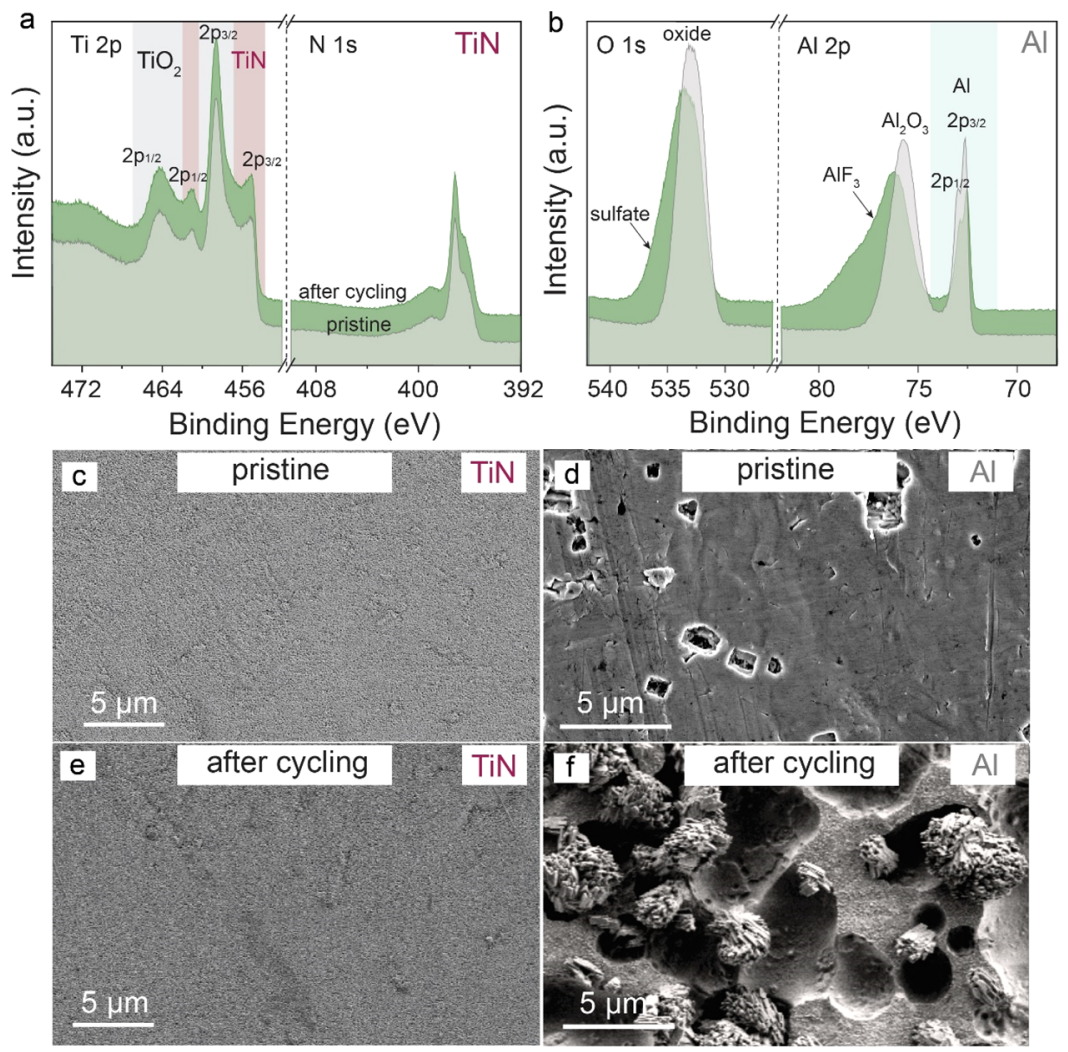

Figure 4. XPS data and SEM images of TiN (a, c, e) and Al (b, d, f) current collectors before and after 1000 galvanostatic charge-discharge cycles with the LMNO cathode in the $4.6 \mathrm{M} \mathrm{LiFSI}$ in EC/DMC electrolyte (see Figure S6 for XPS survey spectra). XPS peaks of $\mathrm{Ti}^{4+}\left(\mathrm{TiO}_{2}\right)$ and $\mathrm{Ti}^{3+}$ $(\mathrm{TiN})$ are indicated by gray and rose bands, respectively. Prior to these measurements, the LMNO cathode was carefully removed from the electrodes and rinsed off with pure EC/DMC solvent.

Coulombic efficiency and cyclic stability of half cells. In fact, a high electrode mass loading (high thickness) can somewhat mask the oxidative instability of current collectors. Thus, two different mass loadings of the LMNO cathode over the TiN 
and $\mathrm{Al}$ current collectors were investigated: a lower mass loading of $1 \mathrm{mg} \mathrm{cm}^{-2}$ (thickness of $15-20 \mu \mathrm{m}$ ) and a higher mass loading of $\sim 4 \mathrm{mg} \mathrm{cm}^{-2}$ (thickness of 55-60 $\mu \mathrm{m}$ ). Further details of electrode preparation and battery assembly can be found in the Supporting Information.

Figure $3 a-d$ and Figure $S 4 a-d$ summarize the results of the electrochemical tests of the $\mathrm{LMNO}$ cathode with $\mathrm{TiN}$ and $\mathrm{Al}$ current collectors at a C-rate of $0.2 \mathrm{C}$ in $4.6 \mathrm{M} \mathrm{LiFSI}$ and $1 \mathrm{M}$ $\mathrm{LiPF}_{6}$ electrolytes, respectively. As follows from Figure $3 \mathrm{a}-\mathrm{d}$ (4.6 M LiFSI electrolyte) for thick LMNO cathodes with TiN and $\mathrm{Al}$ current collectors, relatively high initial Coulombic efficiencies of $78 \%$ and $77 \%$ were observed, which gradually increased after 100 cycles up to $98.5 \%$ and $96.7 \%$, respectively. For thin electrodes, however, a severe decrease of Coulombic efficiency down to $42 \%$ was revealed for the $\mathrm{Al}$ current collector, in contrast to TiN (Figure 3c). The higher Coulombic efficiency of thick LMNO electrodes can be explained by the decrease in the proportion of parasitic irreversible oxidation reactions of the electrolyte on the current collector to the reversible oxidation of LMNO cathode with higher LMNO loading.

As follows from Figure $\mathrm{S} 4 \mathrm{a}-\mathrm{d}$, almost no difference was observed in Coulombic efficiency between LMNO electrodes deposited on $\mathrm{TiN}$ and $\mathrm{Al}$ current collectors for $1 \mathrm{M} \mathrm{LiPF}_{6}$ electolyte. The Coulombic efficecncy was about $80 \%$ and $90 \%$ for thin and thick LMNO cathodes deposited on $\mathrm{Al}$ and $\mathrm{TiN}$ current collectors, respectively. The latter can be explained by lower oxidation stability of $1 \mathrm{M} \mathrm{LiPF}_{6}$ electrolyte with an upper oxidation limit of $4.3 \mathrm{~V}$ vs $\mathrm{Li}^{+} / \mathrm{Li}$ in comparison with $4.6 \mathrm{M}$ LiFSI electrolyte (see Figure S3a,c for tungsten electrode). It should be noted that degradation of the LMNO cathode deposited on both $\mathrm{Al}$ and $\mathrm{TiN}$ current collectors is caused primarily by the $\mathrm{Mn} / \mathrm{Ni}$ dissolution. Although substantial cyclic stability improvements of the LMNO cathode have been made in the past several years using various surface functionalization approaches such as surface modification/ coating/doping, degradation of LMNO cathode during its cycling is still not fully solved. We suggest that future work should be possibly focused on the combination of LMNO cathodes with Li-ion solid-state electrolytes, which can solve the $\mathrm{Mn} / \mathrm{Ni}$ dissolution issues and have a high oxidative stability window of $>5.0 \mathrm{~V} \mathrm{vs} \mathrm{Li}^{+} / \mathrm{Li}$.

To obtain a closer look at the chemical processes at the TiN and $\mathrm{Al}$ surface under the LMNO thick electrodes, their surfaces were examined before and after 1000 galvanostatic charge-discharge cycles (Figure S5) with the LMNO cathode in the $4.6 \mathrm{M}$ LiFSI in EC/DMC electrolyte by X-ray photoelectron spectroscopy (XPS) and SEM. XPS of the TiN current collector suggests that the outermost layers of $\mathrm{Ti}$ atoms are in the $\mathrm{Ti}^{4+}$ state, presumably with oxygen anions as the plane terminating the surface. Nearly identical Ti $2 \mathrm{p}$ and $\mathrm{N}$ 1s XPS bands before and after cycling of TiN revealed the absence of reactivity (Figure 4a). Furthermore, no F 1s or S $2 p$ signals were observed for the cycled TiN current collector (Figure S6b). The $\mathrm{N} / \mathrm{Ti}$ atomic ratios derived from XPS spectra were practically identical before and after cycling (1.0 \pm 0.1 and $1.0 \pm 0.1$, respectively). Apparently, no obvious changes in the surface morphology of TiN current collectors were observed even after 1000 cycles (Figures 4c,e), thus indicating the excellent corrosion resistance of the TiN current collector. In contrast, the surface morphology of $\mathrm{Al}$ was completely changed after cycling (Figures 4d,f) and was composed of relatively large amounts of $S$ and $F$ according to
XPS measurements (Figure $4 \mathrm{~b}$ and Figure S6a). The products of the $\mathrm{Al}$ oxidation in the highly concentrated LiFSI electrolyte could be $\mathrm{AlF}_{3}, \mathrm{Al}_{2}\left(\mathrm{SO}_{4}\right)_{3}$, and $\mathrm{Al}(\mathrm{FSI})_{3}$. As follows from XRD and XPS measurements, we assume that the high oxidative stability of TiN current collectors is caused by the preferred (111) orientation (Figure 2) of the TiN film. Obviously, due to the alternation of $\mathrm{Ti}$ and $\mathrm{N}$ planes, this crystallographic direction is highly suited for passivation of $\mathrm{Ti}^{3+}$ ions (protecting them from deep oxidation to $\mathrm{Ti}^{4+}$ ).

In summary, we report on titanium nitride ( $\mathrm{TiN}$ ) as a compelling current collector material for high-voltage cathode materials that can be easily fabricated by magnetron sputtering on stainless steels or polyimide surfaces on a large scale. Comprehensive characterization of the TiN current collector by XRD, XPS, and SEM revealed its high oxidative stability in $\mathrm{LiPF}_{6}$ and LiFSI electrolytes, exceeding those for SS and $\mathrm{Al}$ current collectors. The high oxidative stability of TiN in combination with a high-voltage LMNO cathode has been assessed. TiN/LMNO electrodes demonstrated a high Coulombic efficiency of $98.5 \%$ at a low C-rate of $0.2 \mathrm{C}$ after 100 cycles. This work indicates further avenues for the commercialization of high-voltage cathode materials such as LMNO for next-generation high-voltage LIBs.

\section{ASSOCIATED CONTENT}

\section{Supporting Information}

The Supporting Information is available free of charge on the ACS Publications website at DOI: 10.1021/acsaem.8b01771.

Additional experimantal details and characterization information presented as Figures S1-S6 (PDF)

\section{AUTHOR INFORMATION}

\section{Corresponding Author}

*E-mail: mvkovalenko@ethz.ch. ORCID

Shutao Wang: 0000-0002-1689-2272

Kostiantyn V. Kravchyk: 0000-0001-6149-193X

Stephan Buecheler: 0000-0003-0942-9965

Maryna I. Bodnarchuk: 0000-0001-6597-3266

Maksym V. Kovalenko: 0000-0002-6396-8938

\section{Author Contributions}

The manuscript was written through the contribution of all authors. All authors have given approval to the final version of the manuscript.

\section{Notes}

The authors declare no competing financial interest.

\section{ACKNOWLEDGMENTS}

This research is part of the activities of SCCER HaE, which is financially supported by the Innosuisse-Swiss Innovation Agency. The authors are grateful to the research facilities of ETH Zurich (ETH Electron Microscopy Center, Department of Chemistry and Applied Biosciences) and Empa (Empa Electron Microscopy Center and Laboratory for Mechanics of Materials \& Nanostructures) for access to the instruments and for technical assistance. The authors thank Sebastian Wagner for help with the photography.

\section{REFERENCES}

(1) Goodenough, J. B.; Park, K. S. The Li-Ion Rechargeable Battery: A Perspective. J. Am. Chem. Soc. 2013, 135, 1167-1176. 
(2) Nitta, N.; Wu, F. X.; Lee, J. T.; Yushin, G. Li-Ion Battery Materials: Present and Future. Mater. Today 2015, 18, 252-264.

(3) Armand, M.; Tarascon, J. M. Building Better Batteries. Nature 2008, 451, 652-657.

(4) Chen, H.; Cong, T. N.; Yang, W.; Tan, C.; Li, Y.; Ding, Y. Progress in Electrical Energy Storage System: A Critical Review. Prog. Nat. Sci. 2009, 19, 291-312.

(5) Fairley, P. Energy Storage: Power Revolution. Nature 2015, 526, S102-S104.

(6) Manthiram, A. An Outlook on Lithium Ion Battery Technology. ACS Cent. Sci. 2017, 3, 1063-1069.

(7) Ma, J.; Hu, P.; Cui, G. L.; Chen, L. Q. Surface and Interface Issues in Spinel $\mathrm{LiNi}_{0.5} \mathrm{Mn}_{1.5} \mathrm{O}_{4}$ : Insights into a Potential Cathode Material for High Energy Density Lithium Ion Batteries. Chem. Mater. 2016, 28, 3578-3606.

(8) Gur, T. M. Review of Electrical Energy Storage Technologies, Materials and Systems: Challenges and Prospects for Large-Scale Storage. Energy Environ. Sci. 2018, 11, 2696.

(9) Zhu, Z.; Yan, H.; Zhang, D.; Li, W.; Lu, Q. Preparation of 4.7V Cathode Material $\mathrm{LiNi}_{0.5} \mathrm{Mn}_{1.5} \mathrm{O}_{4}$ by an Oxalic Acid-Pretreated SolidState Method for Lithium-Ion Secondary Battery. J. Power Sources 2013, 224, 13-19.

(10) Yin, C. J.; Zhou, H. M.; Yang, Z. H.; Li, J. Synthesis and Electrochemical Properties of $\mathrm{LiNi}_{0.5} \mathrm{Mn}_{1.5} \mathrm{O}_{4}$ for Li-Ion Batteries by the Metal-Organic Framework Method. ACS Appl. Mater. Interfaces 2018, 10, 13625-13634.

(11) Yi, T. F.; Mei, J.; Zhu, Y. R. Key Strategies for Enhancing the Cycling Stability and Rate Capacity of $\mathrm{LiNi}_{0.5} \mathrm{Mn}_{1.5} \mathrm{O}_{4}$ as HighVoltage Cathode Materials for High Power Lithium-Ion Batteries. J. Power Sources 2016, 316, 85-105.

(12) Santhanam, R.; Rambabu, B. Research Progress in High Voltage Spinel $\mathrm{LiNi}_{0.5} \mathrm{Mn}_{1.5} \mathrm{O}_{4}$ material. J. Power Sources 2010, 195, $5442-5451$.

(13) Kim, M.; Lee, S.; Kang, B. Fast-Rate Capable Electrode Material with Higher Energy Density than $\mathrm{LiFePO}_{4}: 4.2 \mathrm{~V} \mathrm{LiVPO}_{4} \mathrm{~F}$ Synthesized by Scalable Single-Step Solid-State Reaction. Adv. Sci. 2016, 3, 1500366.

(14) Barker, J.; Gover, R. K. B.; Burns, P.; Bryan, A.; Saidi, M. Y.; Swoyer, J. L. Structural and Electrochemical Properties of Lithium Vanadium Fluorophosphate, $\mathrm{LiVPO}_{4}$ F. J. Power Sources 2005, 146, $516-520$.

(15) Li, Y.; Bai, Y.; Wu, C.; Qian, J.; Chen, G.; Liu, L.; Wang, H.; Zhou, X.; Wu, F. Three-dimensional Fusiform Hierarchical Micro/ Nano $\mathrm{Li}_{1.2} \mathrm{Ni}_{0.2} \mathrm{Mn}_{0.6} \mathrm{O}_{2}$ with a Preferred Orientation (110) Plane as a High Energy Cathode Material for Lithium-Ion Batteries. J. Mater. Chem. A 2016, 4, 5942-5951.

(16) Zhao, T.; Gao, X.; Wei, Z.; Guo, K.; Wu, F.; Li, L.; Chen, R. Three-Dimensional $\mathrm{Li}_{1.2} \mathrm{Ni}_{0.2} \mathrm{Mn}_{0.6} \mathrm{O}_{2}$ Cathode Materials Synthesized by a Novel Hydrothermal Method for Lithium-Ion Batteries. J. Alloys Compd. 2018, 757, 16-23.

(17) Kim, J.; Lee, H.; Cha, H.; Yoon, M.; Park, M.; Cho, J. Prospect and Reality of Ni-Rich Cathode for Commercialization. Adv. Energy Mater. 2018, 8, 1870023.

(18) Lee, J.; Kim, C.; Kang, B. High Electrochemical Performance of High-Voltage $\mathrm{LiNi}_{0.5} \mathrm{Mn}_{1.5} \mathrm{O}_{4}$ by Decoupling the $\mathrm{Ni} / \mathrm{Mn}$ Disordering from the Presence of $\mathrm{Mn}^{3+}$ ions. NPG Asia Mater. 2015, 7, No. e211.

(19) Zhang, X. Y.; Winget, B.; Doeff, M.; Evans, J. W.; Devine, T. M. Corrosion of Aluminum Current Collectors in Lithium-Ion Batteries with Electrolytes Containing $\mathrm{LiPF}_{6}$. J. Electrochem. Soc. 2005, 152, B448-B454.

(20) Ma, T. Y.; Xu, G. L.; Li, Y.; Wang, L.; He, X. M.; Zheng, J. M.; Liu, J.; Engelhard, M. H.; Zapol, P.; Curtiss, L. A.; Jorne, J.; Amine, K.; Chen, Z. H. Revisiting the Corrosion of the Aluminum Current Collector in Lithium-Ion Batteries. J. Phys. Chem. Lett. 2017, 8, 10721077.

(21) Myung, S.-T.; Sasaki, Y.; Sakurada, S.; Sun, Y.-K.; Yashiro, H. Electrochemical behavior of current collectors for lithium batteries in non-aqueous alkyl carbonate solution and surface analysis by ToFSIMS. Electrochim. Acta 2009, 55, 288-297.
(22) Myung, S. T.; Hitoshi, Y.; Sun, Y. K. Electrochemical behavior and passivation of current collectors in lithium-ion batteries. J. Mater. Chem. 2011, 21, 9891-9911.

(23) Campanella, L.; Pistoia, G. $\mathrm{MoO}_{3}$ : A New Electrode Material for Nonaqueous Secondary Battery Applications. J. Electrochem. Soc. 1971, 118, 1905-1908.

(24) Mohamedi, M.; Takahashi, D.; Itoh, T.; Umeda, M.; Uchida, I. ESD fabricated thin films of spinel $\mathrm{LiMn}_{2} \mathrm{O}_{4}$ for lithium microbatteries - I. Effects of thickness. J. Electrochem. Soc. 2002, 149, A19A25.

(25) Nolan, B. G.; Strauss, S. H. Nonaqueous Lithium Battery Electrolytes Based on Bis(polyfluorodiolato)borates. J. Electrochem. Soc. 2003, 150, A1726-A1734.

(26) Sharma, R. A. Compatibility of Molybdenum Current Collectors in Lithium-Alloy/Iron Disulfide Cell Environment. J. Electrochem. Soc. 1989, 136, 3174-3180.

(27) Gavanier, B.; Butt, N. S.; Hutchins, M.; Mercier, V.; Topping, A. J.; Owen, J. R. A Comparison of the Electrochemical Properties of Lithium Intercalated Amorphous and Crystalline Tungsten Oxide. Electrochim. Acta 1999, 44, 3251-3258.

(28) Nishizawa, M.; Uchida, I. Microelectrode-based Characterization Systems for Advanced Materials in Battery and Sensor Applications. Electrochim. Acta 1999, 44, 3629-3637.

(29) Wang, S.; Kravchyk, K. V.; Filippin, A. N.; Müller, U.; Tiwari, A. N.; Buecheler, S.; Bodnarchuk, M. I.; Kovalenko, M. V. Aluminum Chloride-Graphite Batteries with Flexible Current Collectors Prepared from Earth-Abundant Elements. Adv. Sci. 2018, 5, 1700712.

(30) Yamada, Y.; Yamada, A. Review-superconcentrated electrolytes for lithium batteries. J. Electrochem. Soc. 2015, 162, A2406A2423. 